\title{
Nanoscale
}

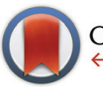

CrossMark

\& click for updates

Cite this: Nanoscale, 2016, 8, 19280

\section{Controlling the lifetimes of dynamic nanoparticle aggregates by spiropyran functionalization $\dagger$}

\author{
Pintu K. Kundu, \$ Sanjib Das, § Johannes Ahrens and Rafal Klajn*
}

Novel light-responsive nanoparticles were synthesized by decorating the surfaces of gold and silver nanoparticles with a nitrospiropyran molecular photoswitch. Upon exposure to UV light in nonpolar solvents, these nanoparticles self-assembled to afford spherical aggregates, which disassembled rapidly when the UV stimulus was turned off. The sizes of these aggregates depended on the nanoparticle concentration, and their lifetimes could be controlled by adjusting the surface concentration of nitrospiropyran on the nanoparticles. The conformational flexibility of nitrospiropyran, which was altered by modifying the structure of the background ligand, had a profound impact on the self-assembly process. By coating the nanoparticles with a spiropyran lacking the nitro group, a conceptually different self-assembly system, relying on a reversible proton transfer, was realized. The resulting particles spontaneously (in the dark) assembled into aggregates that could be readily disassembled upon exposure to blue light.

Received 27th July 2016, Accepted 18th October 2016

DOI: $10.1039 / c 6 n r 05959 g$

www.rsc.org/nanoscale decorating the NPs with azobenzene $e^{23-26}$ and spiropyran $^{21,27-30}$ molecular switches. The resulting NPs are typically stable in nonpolar solvents (such as toluene) on account of the hydrophobic nature of the thermodynamically stable trans-azobenzene isomer and the closed-ring form of spiropyran, respectively. However, exposure to UV light results in the formation of the more polar isomers of the photochromes (cisazobenzene and the open-ring merocyanine, respectively), which triggers NP self-assembly as a consequence of (i) the attractive interactions between the NP-bound switches, ${ }^{26,31}$ and (ii) the loss of solvation layers. ${ }^{23}$ Alternative approaches to assemble NPs using UV light are based on the formation of covalent crosslinks between coumarin-functionalized $\mathrm{NPs}^{22}$ and bridging using metal ions. ${ }^{30}$

Light-controlled self-assembly of NPs has found diverse applications, e.g., in controlling the catalytic properties of nanosystems, ${ }^{32}$ in creating dynamic superparamagnetic coatings for the magnetic guidance and controlled release of diamagnetic "cargo", ${ }^{33}$ as well as in accelerating chemical reactions by means of reversible formation of nanoconfined environments ("dynamically self-assembling nanoflasks"). ${ }^{34}$

Unfortunately, all of the above systems and applications suffer from the drawback that in order to induce a fast backisomerization reaction (and consequently the disassembly of NP aggregates) within short time scales, applying a second stimulus (namely, visible light) is required. In light of this limitation, it would be desired to fabricate NP aggregates that disassemble as soon as the stimulus inducing self-assembly is removed. To attain this goal, we decided to focus on the spiro- 
pyran molecular switch, whose UV-induced form (i.e., merocyanine; MC) is significantly more polar than cis-azobenzene, which should trigger a rapid back-isomerization reaction. Our initial experiments with model compounds confirmed this reasoning: we found that whereas the cis form of a simple azobenzene decayed with a first-order rate constant of $k \approx 0.41$ day $^{-1}$, the open-ring isomer of the parent spiropyran isomerized with $k \approx 0.13 \mathrm{~s}^{-1}$ (in agreement with previous reports ${ }^{35}$ ) i.e., over four orders of magnitude faster (see the ESI, section $2 \dagger)$. Recently, we developed the synthesis of spiropyran-functionalized $\mathrm{Au}_{25}$ nanoclusters and noted a rapid (within 10 minutes) dark disassembly of UV-generated aggregates of these nanoclusters. Working with significantly larger ( 300-900 nm) silica colloids coated with a spiropyran-rich polymer shell, Bell and Piech found that the disassembly in the dark was complete in $>3$ hours. Encouraged by these results, we hypothesized that the dark lifetimes of the aggregates of MC-decorated NPs would be markedly shorter than those assembled from the same NPs functionalized with monolayers of azobenzene, and that it should be possible to control the aggregate lifetimes by adjusting the surface concentration of spiropyran.

\section{Self-assembly of spiropyran- functionalized nanoparticles}

To verify this hypothesis, we synthesized a thiolated spiropyran $(\mathbf{1} \text { in Fig. 1a })^{27}$ and prepared a series of NPs having different sizes and different surface coverages of 1 (see the ESI, section $6 \%$ ). To control the concentration of $\mathbf{1}$ on the surface of small gold NPs, we formed mixed monolayers of $\mathbf{1}$ and a "background" ligand 2. We found that $5.5 \mathrm{~nm}$ Au NPs formed stable suspensions in toluene for coatings containing $\sim 10-70 \%$ of 1 , whereas $2.6 \mathrm{~nm} \mathrm{Au}$ NPs were stable in solution irrespective of the composition of the mixed monolayer. For $11 \mathrm{~nm}$ silver NPs, we had to resort to another background ligand, 11-phenoxyundecanethiol ${ }^{36}$ 3 , to render the particles stable in toluene (which was the case with 1 : 3 molar ratios lower than $c a .50 \%)$. a)

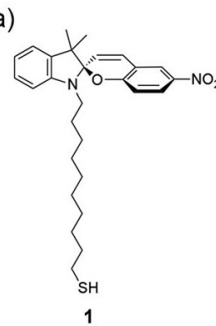

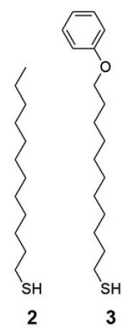
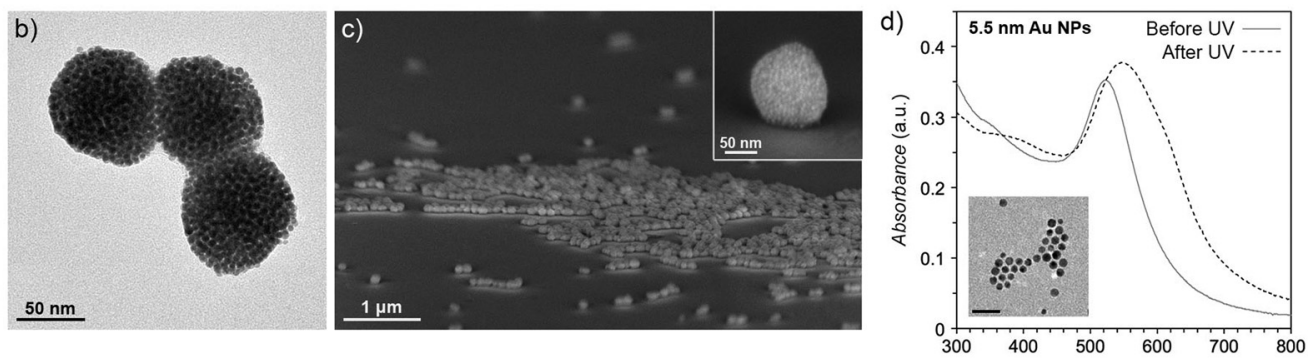

e)

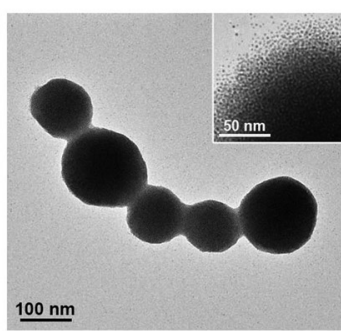

g)
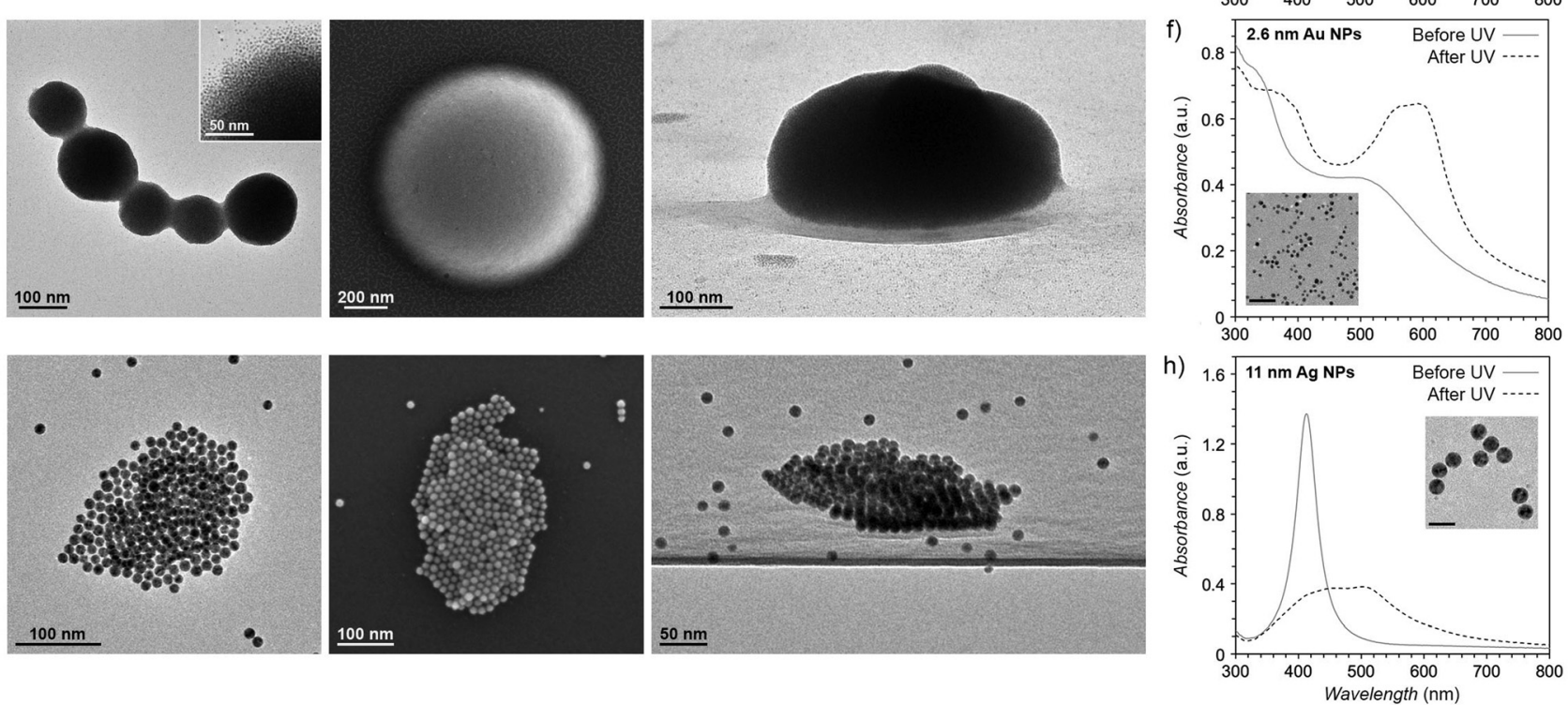

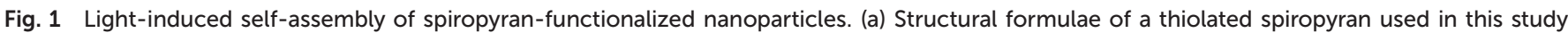

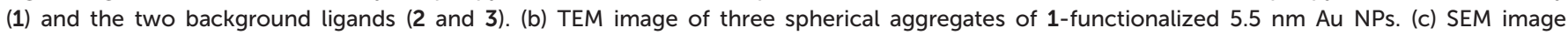

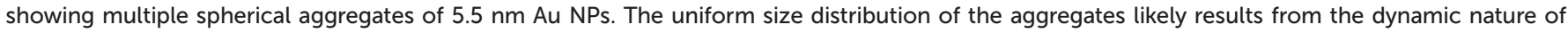

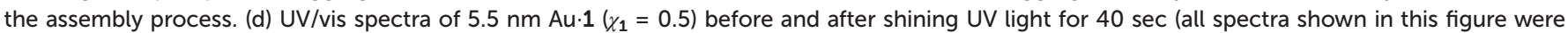

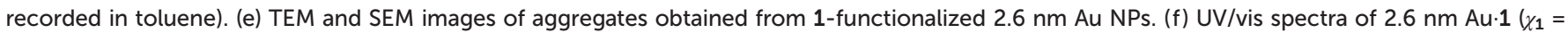

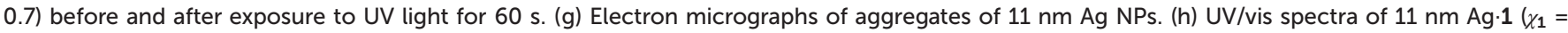
0.15 ) before and after exposure to UV light for $2 \mathrm{~min}$. Scale bars in (d), (f), and (h) correspond to $20 \mathrm{~nm}$. 
When the toluene solutions of 1-functionalized nanoparticles were exposed to low-intensity $\left(\sim 0.7 \mathrm{~mW} \mathrm{~cm}^{-2}\right)$ $365 \mathrm{~nm}$ UV radiation, rapid self-assembly commenced, resulting in spherical aggregates akin to those obtained from azobenzene-coated NPs. ${ }^{25,26,37}$ The self-assembly was triggered by light-induced isomerization of spiropyran (SP) to the highly polar MC isomer ${ }^{38-40}$ (note that in order to minimize the electronic interactions between the photoswitch and the metals, we separated the spiropyran moiety from the NP surface with a long alkyl linker ${ }^{41}$ ). The isomerization resulted in desolvation of the NP surfaces in nonpolar toluene and possible MC-MC interactions ${ }^{42}$ within the same NP or between different NPs. A critical number of MC units per NP was required to induce the attractive interparticle interactions: we studied this dependence systematically for $2.6 \mathrm{~nm}$ NPs, where we varied the relative molar content of 1 on the NP surfaces $\left(n_{1} /\left(n_{1}+n_{2}\right)\right.$, denoted $\chi_{\mathbf{1}}$ ), and established that the transition occurred at 0.5 $<\chi_{1}<0.6$. In other words, out of $\sim 99$ thiolate ligands which each $2.6 \mathrm{~nm} \mathrm{NP}$ is capable of accommodating, at least 49-59 must be 1 for the assembly to be initiated (see also the discussion in the ESI, section $7 \dagger$ ).

NP aggregation was accompanied by a red shift of the localized surface plasmon resonance (SPR) band, which we followed to gain insights into the kinetics of aggregation (note that the SPR band of Au NPs overlaps with the absorption of the MC form of the switch). Section 8 in the ESI, $\uparrow$ for example, shows the evolution of the UV/vis spectra of 1-functionalized $5.5 \mathrm{~nm} \mathrm{Au} \mathrm{NPs} \mathrm{(at} \chi_{1}=0.5$ ) exposed to UV light for different time periods. The spectra show that no further changes in $\lambda_{\mathrm{SPR}}$ occur beyond the initial 40 seconds of UV irradiation; similarly, we determined the shortest irradiation times needed to complete the assembly of other types of NPs, and employed these times in the subsequent (disassembly) experiments. In all cases, NP aggregation was confirmed by dynamic light scattering (DLS) and transmission and scanning electron microscopy (TEM and SEM, respectively) (Fig. 1). Note that sample preparation for TEM/SEM imaging is challenging because of the dynamic nature of our NP aggregates, which begin to disassemble as soon as UV light is switched off (see Fig. 1e, inset). We found that the extent of disassembly could be limited by depositing solutions of the aggregates and evaporating the solvent under continuous exposure to UV light. Whereas this method allowed us to roughly preserve the spherical structures of Au NP aggregates (Fig. 1b, c and e), the assemblies of $\mathrm{Ag}$ NPs became deformed and disassembled more readily (Fig. 19). We speculate that this behavior of $\mathrm{Ag}$ NP aggregates is due to the limited conformational flexibility ${ }^{43}$ (and hence the ability to form MC-MC contacts efficiently) of the MC units on the surfaces of Ag NPs - these nanoparticles, in addition to being relatively large (hence having small curvature), host the relatively long molecule 3 as the background ligand.

\section{Controlling the sizes of dynamic nanoparticle aggregates}

The different sizes of the aggregates of $2.6 \mathrm{~nm}$ Au NPs, $5.5 \mathrm{~nm}$ $\mathrm{Au}$ NPs, and $11 \mathrm{~nm} \mathrm{Ag} \mathrm{NPs} \mathrm{as} \mathrm{shown} \mathrm{in} \mathrm{Fig.} 1$ result from different NP concentrations in the solutions exposed to UV light. To demonstrate the effect of concentration directly, we diluted a $c_{\mathrm{Au}}=3.45 \mathrm{mM}$ stock solution of $5.5 \mathrm{~nm} \mathrm{Au} \cdot 1\left(\chi_{1}=0.5\right)$ by factors of $\sim 2, \sim 4$, and $\sim 8$, and subjected the resulting solutions to UV light under otherwise identical conditions. As Fig. 2a-c show self-assembly at increasing dilutions caused a gradual decrease in both (i) the $\lambda_{\text {SPR }}$ of the aggregated NPs and (ii) the overall absorbance in the red part of the spectrum; both trends are indicative of decreasing aggregate dimensions. The dilution effect was confirmed by DLS studies, which, interestingly, showed that the solvodynamic diameters of the aggre-
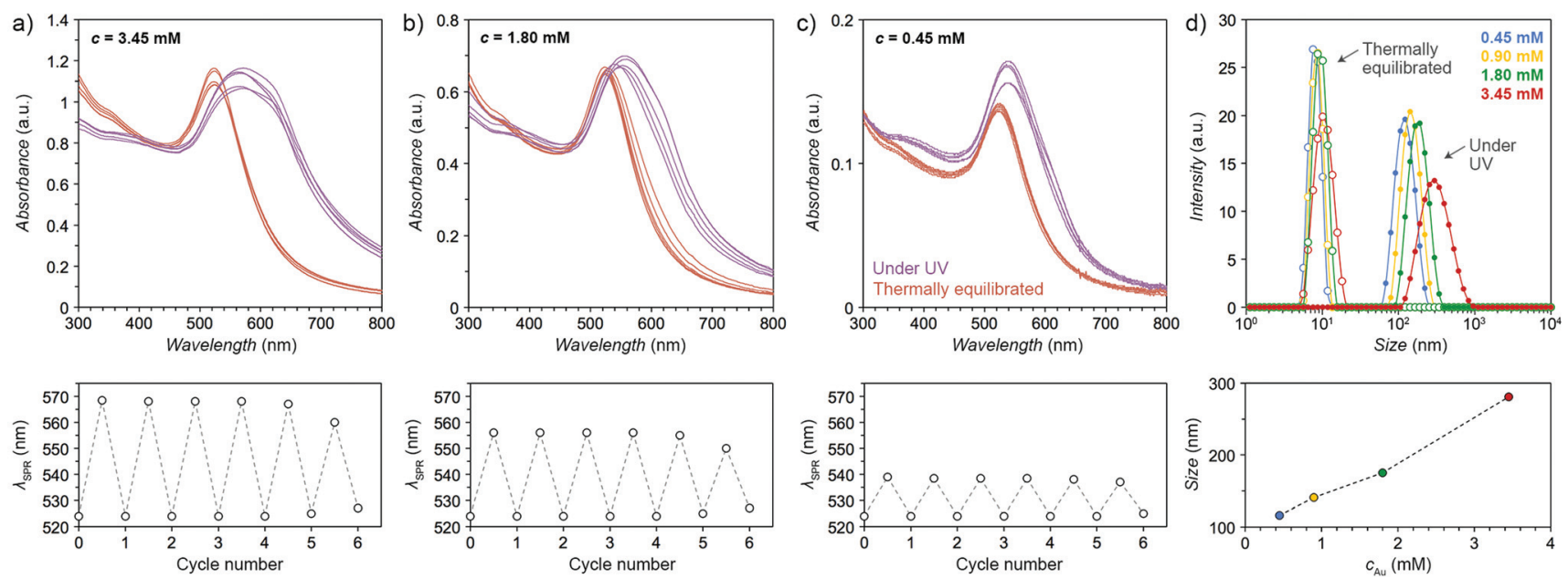

Fig. 2 Controlling the aggregate sizes. (a-c) Light-controlled self-assembly of $5.5 \mathrm{~nm} \mathrm{Au} \mathrm{NPs}\left(\chi_{1}=0.5\right)$ at three different concentrations: $3.45 \mathrm{mM}$ (a), $1.80 \mathrm{mM}$ (b), and $0.45 \mathrm{mM}$ (c) (concentrations in terms of Au atoms). Repeated spectra correspond to consecutive assembly-disassembly cycles. (d) DLS profiles of the same NPs before (empty markers) and after (solid markers) exposure to UV light for different nanoparticle concentrations. 
gates scaled roughly linearly with the concentration of the primary particles in the solution (Fig. 2d). Subsequent disassembly-assembly cycles resulted in aggregates of reproducible dimensions, as shown in the bottom panels of Fig. 2a-c. Unfortunately, UV-induced isomerization of spiropyran resulted in a gradual photodecomposition (fatigue) of the molecule, ${ }^{42}$ which limited the number of assembly-disassembly cycles to $\sim 30$.

\section{Controlling the lifetimes of dynamic nanoparticle aggregates}

Next, we investigated the kinetics of the dark disassembly of $\mathrm{NP}$ aggregates. Typical results (here, for $5.5 \mathrm{~nm} \mathrm{Au} \cdot \mathbf{1}$ at $\chi_{\mathbf{1}}=0.5$ and $c_{\mathrm{Au}}=1.8 \mathrm{mM}$ ) are shown in Fig. 3a, where $t=0$ denotes a spectrum recorded immediately after UV light was turned off (note that it took $\sim 5 \mathrm{~s}$ to record a full-range spectrum), and the subsequent spectra correspond to different dark adaptation times. Although the disassembly commenced immediately after switching off the light, with a complete disassembly achieved within $c a .20$ minutes, the process was significantly slower than what might be expected from the kinetics of $\mathrm{MC}$ $\rightarrow$ SP back-isomerization (ESI, section $2 \dagger$ ). To better understand these results, we synthesized $2.6 \mathrm{~nm}$ Au NPs functionalized with a mixed monolayer of $\mathbf{1}$ and 2 , with an amount of $\mathbf{1}$ insufficient to induce NP aggregation in toluene (we used $\chi_{\mathbf{1}}=$ 0.33 ) - these NPs allowed us to study the on-nanoparticle back-
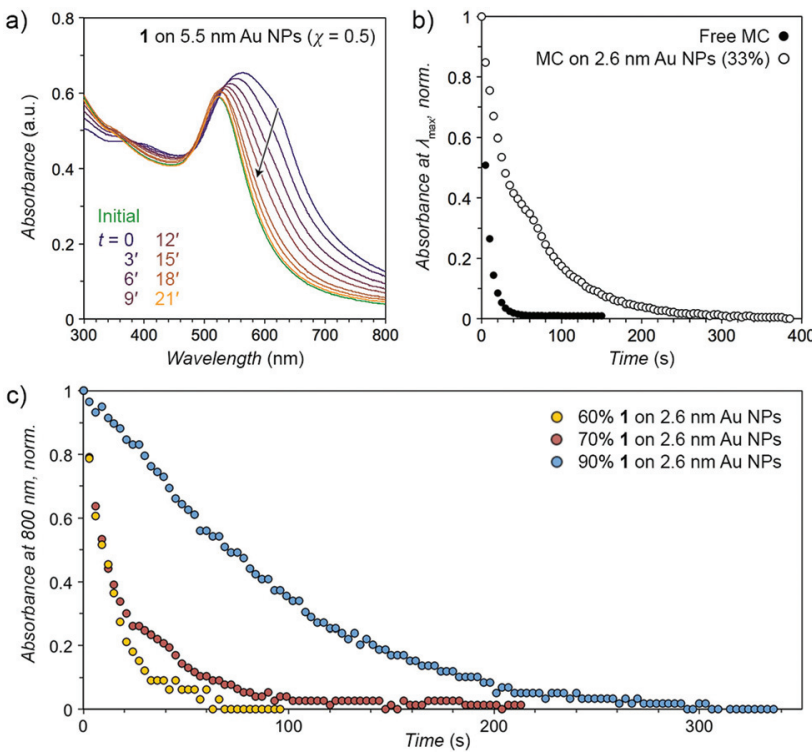

Fig. 3 Rapid disassembly of nanoparticle aggregates in the dark (all measurements were performed in toluene at room temperature). (a) Changes in the UV/vis spectra of $5.5 \mathrm{~nm}$ Au NP aggregates $\left(\chi_{1}=0.5\right)$ upon dark incubation. (b) Comparison of the kinetics of MC $\rightarrow$ SP backisomerization in solution (solid markers) and on the surface of $2.6 \mathrm{~nm}$ nanoparticles (empty markers). (c) Kinetics of the disassembly of $2.6 \mathrm{~nm}$ Au NP aggregates as a function of $\chi_{1}$. isomerization reaction without it being influenced by interparticle interactions, and without the UV/vis spectra being obscured by NP aggregation. Interestingly, we found that when attached to the NPs, the MC switched several times slower than in solution, and that the MC decay could not be fitted to a monoexponential function. These results point to the presence of attractive interactions between MC units residing on the same nanoparticle, which suggests that such interactions can also take place between MCs on different NPs (a less likely explanation involves interactions between the MC and the SP forms ${ }^{42}$ ). This reasoning, along with the previous observations on MC-MC interactions decelerating the MC $\rightarrow$ SP back-isomerization, ${ }^{44,45}$ can largely explain the relatively slow kinetics of the NP aggregate disassembly.

Disassembly of NP aggregates could be conveniently followed by monitoring the decay of absorbance at $800 \mathrm{~nm}\left(A_{800}\right)$ (see Fig. 3a). Fig. 3c shows the decomposition kinetics of $2.6 \mathrm{~nm}$ Au NP aggregates at three different values of $\chi_{1}$. In all cases, disassembly was complete within $5 \mathrm{~min}$ in the dark, that is, approximately two orders of magnitude faster than that for aggregates generated from azobenzene-coated NPs. ${ }^{41}$ Importantly, the lifetimes of the aggregates could be controlled by the surface concentration of spiropyran; for example, increasing $\chi_{1}$ from 0.6 (Fig. 3c, yellow markers) to 0.9 (blue markers) shifted the time required to decrease $A_{800}$ by half from $\sim 9 \mathrm{~s}$ to $\sim 72 \mathrm{~s}$. These results can be explained by the relatively high number of MC-MC contacts between NPs having high $\chi_{1}$ values.

Interestingly, there is a marked difference in the behavior of our 1-functionalized NPs and those of Shiraishi and coworkers, who also synthesized spiropyran-decorated Au NPs. Whereas our NP aggregates disassembled rapidly in the dark (vide infra), the ones prepared previously required exposure to visible light to disintegrate. These contrasting behaviors could be attributed to different degrees of conformational freedom of spiropyran. Shiraishi et al. decorated their NPs with a monocomponent monolayer of a ligand in which the spiropyran moiety was separated from the mercapto group by a short linker. ${ }^{21}$ This scenario entails the presence of MC-MC interactions upon NP assembly, which require exposure to visible light to break. ${ }^{42}$ In contrast, the strong lateral van der Waals interactions between the long alkyl chains of the NP-bound ligands limit the conformational freedom of the MC in our case, with NP surface desolvation being the main driving force behind the aggregation.

The above reasoning is corroborated by additional experiments, in which we synthesized 1-functionalized $2.6 \mathrm{~nm} \mathrm{Au}$ NPs (at $\chi_{1}=0.5$ ) with 1-hexanethiol as the background ligand (ESI, section $10 \dagger$ ). We found, interestingly, that (i) these NPs readily self-assembled upon exposure to UV light (recall that $\chi_{1}$ $=0.5 \mathrm{Au}$ NPs of the same size with 1-dodecanethiol as the background ligand did not aggregate) and (ii) the resulting aggregates disintegrated only partially in the dark, and required exposure to visible light to disassemble completely. These observations can be rationalized by (i) the relatively high conformational freedom of spiropyran on NPs functionalized 
with short background ligands, and (ii) consequently, facilitated formation of MC-MC contacts.

\section{Nanoparticle self-assembly based on reversible proton transfer}

Finally, in an attempt to further decrease the lifetime of lightinduced NP aggregates, we synthesized a novel thiolated spiropyran 4 (Fig. 4a) and co-assembled it on $5.5 \mathrm{~nm}$ Au NPs with 2 as the background ligand. Compared with $\mathbf{1}$, spiropyran $\mathbf{4}$ lacks the nitro group, which significantly destabilizes the open-ring MC isomer, facilitating the back-isomerization reaction. ${ }^{46}$ The solutions of 4 -functionalized $5.5 \mathrm{~nm} \mathrm{Au} \mathrm{NPs} \mathrm{were}$ stable in toluene for relative molar contents of $\mathbf{4}, \chi_{\mathbf{4}}$, in the range of 0.2-0.5; however, attempts to assemble these NPs using UV light failed. This result can be attributed to the poor yield of the light-induced ring-opening reaction of $\mathbf{4}$ in toluene, estimated using transient absorption spectroscopy at $\sim 10 \%$. At the same time, we found that these NPs could be assembled upon the addition of strong acids, which could induce ring opening by generating the protonated merocyanine $\left(\mathrm{MCH}^{+}\right)$species (Fig. 4a, left), which, owing to its highly polar character, induced destabilization of the NPs in the nonpolar toluene. $\mathrm{MCH}^{+}$exhibits an intense absorption band centered at $\sim 420 \mathrm{~nm}$ (corresponding to the absorption of blue light) and it acts as a photoacid: irradiating solutions of $\mathrm{MCH}^{+}$ with blue light releases $\mathrm{H}^{+}$while regenerating the SP form. ${ }^{4-49}$ Indeed, exposing the NP aggregates to a blue LED induced their disassembly, affording a solution similar to the one before the $\mathrm{H}^{+}$addition (Fig. 4a, right). TEM studies revealed that the NPs were quantitatively assembled and fully disassembled in the dark and under blue light, respectively (Fig. 4b). The light-induced disassembly process took less than one minute to complete, whereas the dark assembly occurred within an hour (see the series of spectra in Fig. 4c). Importantly, the disassembly-assembly sequence could be repeated multiple times without any appreciable fatigue (Fig. 4d and e) (we observed no deterioration in the performance of the system after 50 cycles). This mode of NP assembly is akin to a recently reported system, whereby a small-molecule photoacid reversibly promoted attractive interparticle interactions by protonating/deprotonating functionalized nanoparticles. ${ }^{50}$

\section{Conclusions}

We synthesized a family of spiropyran-functionalized nanoparticles and showed that their aggregates disassemble rapidly when the stimulus used for their formation (UV light) is turned off. Interestingly, these results parallel the early studies of Irie and co-workers, ${ }^{51,52}$ who investigated the light-induced viscosity changes of benzene solutions of poly(methyl methacrylate) having pendant spiropyran groups, and found that the viscosity of UV-irradiated solutions returned to the original values within 3 minutes in the dark. The lifetime of our NP aggregates could be controlled by adjusting the surface concentration of the spiropyran moieties. The limited stability of spiropyran to UV light (we could perform up to 30 assembly-
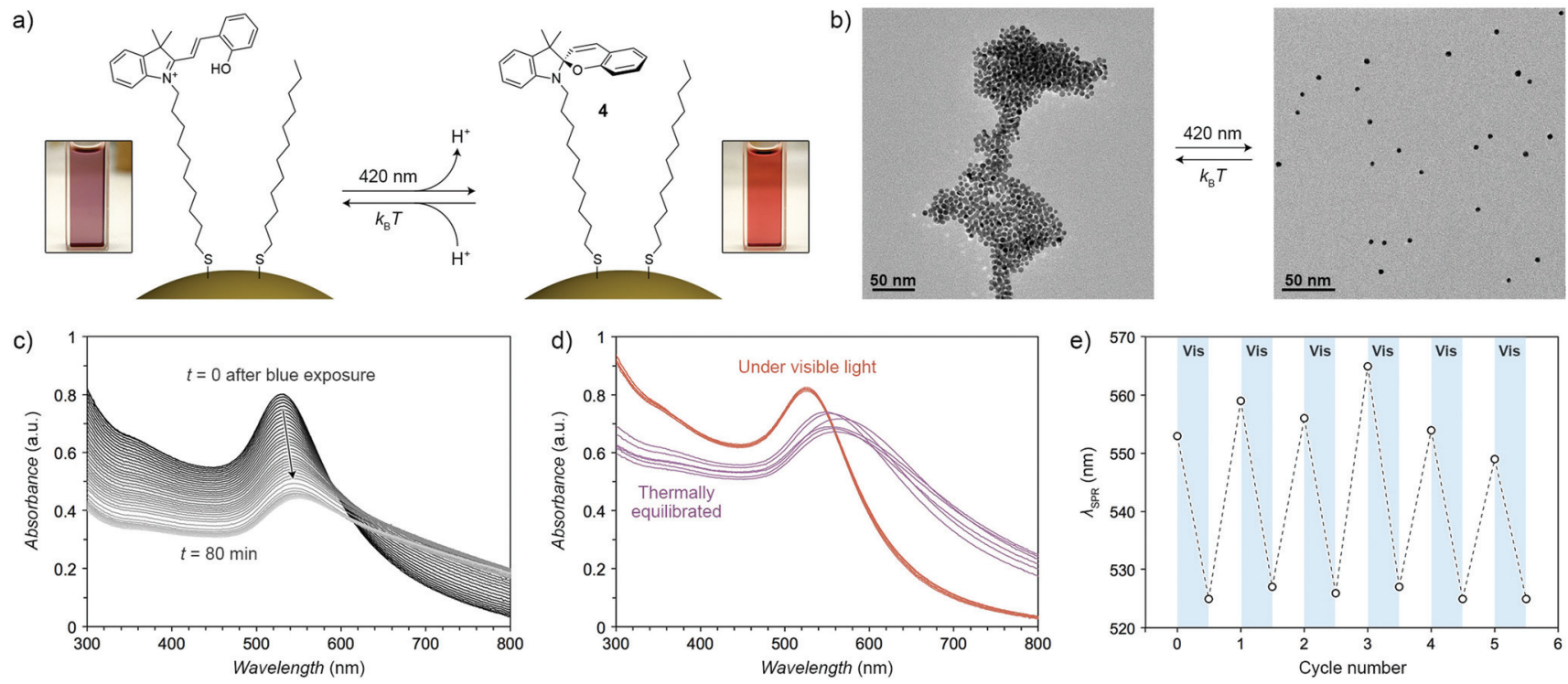

Fig. 4 Blue light-induced aggregation of 4-functionalized NPs. (a) $\mathrm{MCH}^{+}$-coated Au NPs spontaneously assemble in toluene. Irradiation with blue light disassembles aggregates as a result of the $\mathrm{MCH}^{+} \rightarrow \mathrm{SP}+\mathrm{H}^{+}$reaction. The reaction is reversed in the dark, which triggers $\mathrm{NP}$ re-assembly. (b) TEM images of NPs equilibrated in the dark (left) and exposed to blue light (right) $\left(\chi_{4}=0.35\right)$. (c) Evolution of the absorption spectra of 4-functionalized NPs in the dark following exposure to blue light. (d) UV/vis spectra of NPs under blue light (red) and in the dark (purple). Repeated spectra correspond to consecutive assembly-disassembly cycles. (e) Changes in the position of the SPR peak as a result of exposure to blue light and dark incubation. 
disassembly cycles) could be tackled by resorting to the more stable spirooxazine derivatives in the future. ${ }^{53,54}$ Finally, we described a novel NP self-assembly system based on surfaceimmobilized photoacid - this system could be actuated using blue light and it exhibited excellent photostability. Ongoing efforts in our laboratory are aimed at obtaining reversibly selfassembling systems in aqueous environments.

\section{Acknowledgements}

This work was supported by the European Research Council (grant no. 336080).

\section{References}

1 M. Grzelczak, J. Vermant, E. M. Furst and L. M. LizMarzán, ACS Nano, 2010, 4, 3591-3605.

2 R. Klajn, J. F. Stoddart and B. A. Grzybowski, Chem. Soc. Rev., 2010, 39, 2203-2237.

3 L. M. Liz-Marzán, Langmuir, 2006, 22, 32-41.

4 E. V. Shevchenko, M. Ringler, A. Schwemer, D. V. Talapin, T. A. Klar, A. L. Rogach, J. Feldmann and A. P. Alivisatos, J. Am. Chem. Soc., 2008, 130, 3274-3275.

5 J. Chen, A. G. Dong, J. Cai, X. C. Ye, Y. J. Kang, J. M. Kikkawa and C. B. Murray, Nano Lett., 2010, 10, 51035108.

6 E. Garcia-Berrios, T. Gao, M. D. Woodka, S. Maldonado, B. S. Brunschwig, M. W. Ellsworth and N. S. Lewis, J. Phys. Chem. C, 2010, 114, 21914-21920.

7 M. V. Kovalenko, M. Scheele and D. V. Talapin, Science, 2009, 324, 1417-1420.

8 R. W. Taylor, T. C. Lee, O. A. Scherman, R. Esteban, J. Aizpurua, F. M. Huang, J. J. Baumberg and S. Mahajan, ACS Nano, 2011, 5, 3878-3887.

9 S. T. Jones, R. W. Taylor, R. Esteban, E. K. Abo-Hamed, P. H. H. Bomans, N. Sommerdijk, J. Aizpurua, J. J. Baumberg and O. A. Scherman, Small, 2014, 10, 42984303.

10 E. A. Osborne, B. R. Jarrett, C. Q. Tu and A. Y. Louie, J. Am. Chem. Soc., 2010, 132, 5934-5934.

11 Q. Zhang, D. H. Qu, Q. C. Wang and H. Tian, Angew. Chem., Int. Ed., 2015, 54, 15789-15793.

12 R. J. Coulston, S. T. Jones, T. C. Lee, E. A. Appel and O. A. Scherman, Chem. Commun., 2011, 47, 164-166.

13 R. Klajn, M. A. Olson, P. J. Wesson, L. Fang, A. Coskun, A. Trabolsi, S. Soh, J. F. Stoddart and B. A. Grzybowski, Nat. Chem., 2009, 1, 733-738.

14 A. Winter, M. D. Hager, G. R. Newkome and U. S. Schubert, Adv. Mater., 2011, 23, 5728-5748.

15 D. B. Liu, W. W. Chen, K. Sun, K. Deng, W. Zhang, Z. Wang and X. Y. Jiang, Angew. Chem., Int. Ed., 2011, 50, 4103-4107.

16 C. A. Mirkin, R. L. Letsinger, R. C. Mucic and J. J. Storhoff, Nature, 1996, 382, 607-609.
17 J. Elbaz, A. Cecconello, Z. Y. Fan, A. O. Govorov and I. Willner, Nat. Commun., 2013, 4, 2000.

18 S. Ito, H. Yamauchi, M. Tamura, S. Hidaka, H. Hattori, T. Hamada, K. Nishida, S. Tokonami, T. Itoh, H. Miyasaka and T. Iida, Sci. Rep., 2013, 3, 3047.

19 H. Han, J. Y. Lee and X. M. Lu, Chem. Commun., 2013, 49, 6122-6124.

20 J. A. Krings, B. Vonhoren, P. Tegeder, V. Siozios, M. Peterlechner and B. J. Ravoo, J. Mater. Chem. A, 2014, 2, 9587-9593.

21 Y. Shiraishi, E. Shirakawa, K. Tanaka, H. Sakamoto, S. Ichikawa and T. Hirai, ACS Appl. Mater. Interfaces, 2014, 6, 7554-7562.

22 H. B. He, M. Feng, Q. D. Chen, X. Q. Zhang and H. B. Zhan, Angew. Chem., Int. Ed., 2016, 55, 936-940.

23 A. Manna, P. L. Chen, H. Akiyama, T. X. Wei, K. Tamada and W. Knoll, Chem. Mater., 2003, 15, 20-28.

24 A. Köhntopp, A. Dabrowski, M. Malicki and F. Temps, Chem. Commun., 2014, 50, 10105-10107.

25 J.-W. Lee and R. Klajn, Chem. Commun., 2015, 51, 20362039.

26 R. Klajn, K. J. M. Bishop and B. A. Grzybowski, Proc. Natl. Acad. Sci. U. S. A., 2007, 104, 10305-10309.

27 T. Udayabhaskararao, P. K. Kundu, J. Ahrens and R. Klajn, ChemPhysChem, 2016, 17, 1805-1809.

28 M. Ueda, H. B. Kim and K. Ichimura, J. Mater. Chem., 1994, 4, 883-889.

29 N. S. Bell and M. Piech, Langmuir, 2006, 22, 1420-1427.

30 D. B. Liu, W. W. Chen, K. Sun, K. Deng, W. Zhang, Z. Wang and X. Y. Jiang, Angew. Chem., Int. Ed., 2011, 50, 4103-4107.

31 R. Klajn, P. J. Wesson, K. J. M. Bishop and B. A. Grzybowski, Angew. Chem., Int. Ed., 2009, 48, 70357039.

32 Y. H. Wei, S. B. Han, J. Kim, S. L. Soh and B. A. Grzybowski, J. Am. Chem. Soc., 2010, 132, 11018-11020.

33 O. Chovnik, R. Balgley, J. R. Goldman and R. Klajn, J. Am. Chem. Soc., 2012, 134, 19564-19567.

34 H. Zhao, S. Sen, T. Udayabhaskararao, M. Sawczyk, K. Kučanda, D. Manna, P. K. Kundu, J.-W. Lee, P. Král and R. Klajn, Nat. Nanotechnol., 2016, 11, 82-88.

35 V. Z. Shirinian, V. A. Barachevsky, A. A. Shimkin, M. M. Krayushkin, A. K. Mailian, D. V. Tsyganov, O. A. Vinter and O. V. Venidiktova, Russ. Chem. Bull., 2010, 59, 828-832.

36 T. Moldt, D. Brete, D. Przyrembel, S. Das, J. R. Goldman, P. K. Kundu, C. Gahl, R. Klajn and M. Weinelt, Langmuir, 2015, 31, 1048-1057.

37 D. Manna, T. Udayabhaskararao, H. Zhao and R. Klajn, Angew. Chem., Int. Ed., 2015, 54, 12394-12397.

38 E. Fischer and Y. Hirshberg, J. Chem. Soc., 1952, 45224524.

39 G. Berkovic, V. Krongauz and V. Weiss, Chem. Rev., 2000, 100, 1741-1753.

40 V. I. Minkin, Chem. Rev., 2004, 104, 2751-2776.

41 J. Zhang, J. K. Whitesell and M. A. Fox, Chem. Mater., 2001, 7, 2323-2331.

42 R. Klajn, Chem. Soc. Rev., 2014, 43, 148-184. 
43 T. Zdobinsky, P. S. Maiti and R. Klajn, J. Am. Chem. Soc., 2014, 136, 2711-2714.

44 E. Goldburt, F. Shvartsman and V. Krongauz, Macromolecules, 1984, 17, 1876-1878.

45 P. K. Kundu, G. L. Olsen, V. Kiss and R. Klajn, Nat. Commun., 2014, 5, 3588.

46 R. Kiesswetter, N. Pustet, F. Brandl and A. Mannschreck, Tetrahedron: Asymmetry, 1999, 10, 4677-4687.

47 Z. Shi, P. Peng, D. Strohecker and Y. Liao, J. Am. Chem. Soc., 2011, 133, 14699-14703.

48 J. Boekhoven, J. M. Poolman, C. Maity, F. Li, L. van der Mee, C. B. Minkenberg, E. Mendes, J. H. van Esch and R. Eelkema, Nat. Chem., 2013, 5, 433-437.
49 L. A. Tatum, J. T. Foy and I. Aprahamian, J. Am. Chem. Soc., 2014, 136, 17438-17441.

50 P. K. Kundu, D. Samanta, R. Leizrowice, B. Margulis, H. Zhao, M. Börner, T. Udayabhaskararao, D. Manna and R. Klajn, Nat. Chem., 2015, 7, 646-652.

51 M. Irie, A. Menju and K. Hayashi, Macromolecules, 1979, 12, 1176-1180.

52 M. Irie, A. Menju, K. Hayashi and G. Smets, J. Polym. Sci., Part C: Polym. Lett., 1979, 17, 29-31.

53 R. A. Kopelman, S. M. Snyder and N. L. Frank, J. Am. Chem. Soc., 2003, 66, 13684-13685.

54 G. Berkovic, V. Krongauz and V. Weiss, Chem. Rev., 2000, 100, 1741-1753. 